\title{
Candomblé no Brasil: Traçando uma Nova Geografia Social de Gênero, Raça e Classe, a partir de uma Proposta de Sociabilidade Outra
}

\author{
Candomble in Brazil: mapping a new social geography of gender, race and class \\ from a proposal for another sociability
}

\section{Estela Martini Willeman}

Pontifícia Universidade Católica do Rio de Janeiro martiniwill@yahoo.com.br

\section{Resumo}

O presente trabalho tem por propósito resgatar as origens do preconceito e da discriminação de gênero, raça e classe, para observar seus reflexos no campo religioso dentro do Brasil, bem como as formas de resistência efetuadas por estes grupos alijados das condições materiais e simbólicas de produção e reprodução, desde os primórdios da formação social do país. Através do tratamento de aspectos da diáspora africana no Brasil e da análise de inspiração etnográfica com foco empírico em uma das casas de candomblé mais tradicionais e respeitadas do Rio de Janeiro, O Ilê Omiojuarô, matriz e exemplo para várias outras, com representatividade nacional e internacional e situada no município de Nova Iguaçu - Baixada Fluminense - RJ, pretendemos trazer para a discussão política e teórica os discursos e práticas construídos por esse povo que ousa propor uma nova geografia social e uma nova práxis, em busca de reconhecimento e dignidade.

Palavras-chave: Candomblé no Rio de Janeiro; relações de gênero; raça e racismos no Brasil

\begin{abstract}
The purpose of this work is to rescue the origins of prejudice and discrimination based on gender, race and class, to observe its effects in the religious field within Brazil as well as the forms of resistance made by these groups deprived of the material and symbolic conditions of production and reproduction since the beginnings of the social formation of the country. Through the treatment of some aspects of African diaspora in Brazil and an ethnographically based analysis with an empirical focus on one of the most traditional and prestigious candomble houses in Rio de Janeiro, the Ilê Omiojuarô, a matrix and an example for many others, with national and international importance, and located in Nova Iguaçu - Baixada Fluminense - RJ, we intend to bring to the political and theoretical discussions the discourses and practices built by this people who dare to propose a new social geography and a new praxis in their search for recognition and dignity.
\end{abstract}

Keywords: Candomble in Rio de Janeiro; gender relations; race and racism in Brazil 
Candomblé no Brasil: Traçando uma Nova

Geografia Social de Gênero, Raça e Classe, a

partir de uma Proposta de Sociabilidade Outra

\section{Introdução}

O presente artigo é fruto do amadurecimento de nosso investimento acadêmico das temáticas relativas à raça/racismo e gênero no Brasil, a partir de nossas pesquisas que foram vinculadas ao NIEGRE1 no período entre os anos de 2008 e 2009. Em uma de nossas pesquisas vinculadas a este núcleo, nossa intenção foi a de resgatar os impactos da divisão de classes, bem como a utilidade do preconceito e da discriminação racia ${ }^{1}$ e de gênero para manutenção desta segmentação na sociedade capitalista contemporânea, afim de melhor visualizar seus reflexos no campo religioso de matriz afrodescendente - em especial, o Candomblé do Rio de Janeiro. Resgatamos alguns aspectos da ideologia de gênero e do racismo no Brasil para auxiliar nas reflexões propiciadas por nosso trabalho de inspiração etnográfica no Ilê Omi Ojuarô, chefiado por Beatriz Moreira Costa - a Mãe Beata de Iemonjá ${ }^{2}$ situado em Nova Iguaçu, Baixada Fluminense - Rio de Janeiro.

Já de início, devemos informar que nossa orientação para interpretação desta conjuntura é a que compreende o preconceito religioso em relação aos negros brasileiros adeptos de religiões de matrizes africanas no Brasil, em sua maior parte, fruto dos interesses de classe das elites dominantes (brancos, homens, heterossexuais, cristãos, ricos, ocidentais) que, na empreitada de manutenção de sua dominação econômica e de seu status quo, se apoiam firmemente, no plano do simbólico, em construções ideológicas de cunho racista, machista, e de outras naturezas discriminatórias e hierarquizantes. Para superação das estratificações sociais postas, cremos ser necessárias a médio e longo prazo ações socioeducativas focalizadas nas desconstruções e reconstruções morais e éticas, mas, concomitantemente, políticas imediatas no plano material, como as cotas para os grupos considerados invisibilizados, estigmatizados e, portanto, socialmente vulneráveis.

Como bem nos alerta Munanga $(2009)^{3}$ a propósito das cotas para negros em universidades públicas, forma de compensação aos impactos subjetivos e objetivos do 'racismo à brasileira', verificados pela diferença econômica da população negra brasileira em relação aos grupos brancos, o racismo é cotidiano na sociedade brasileira. Segundo ele:

As pessoas que estão contra cotas pensam como se o racismo não tivesse existido na sociedade, não estivesse criando vítimas. Se alguém comprovar que não tem mais racismo no Brasil, não devemos mais falar em cotas para negros. Deveríamos falar só de classes sociais. Mas como o racismo ainda existe, então não há como você tratar igualmente as pessoas que são vítimas de racismo e da questão econômica em relação àquelas que não sofrem esse tipo de preconceito. A própria pesquisa do IPEA mostra que se não mudar esse quadro, os negros vão levar muitos e muitos anos para chegar onde estão os brancos em matéria de educação. (s/p.)

Por fim, observamos como se desenvolve no espaço das comunidades de terreiro a tentativa de garantir a essa população o respeito e dignidade inerentes à cidadania de fato na sociedade de forma mais ampla.

\section{Formação Social, Histórica e Econômica do País}

De acordo com Freyre (1992), para a nossa formação deve ser considerado aquilo que pode ser entendido como virtudes e também defeitos. Podemos perceber que o autor considera, em sua obra, que a harmonia nas relações raciais seriam as 'virtudes'. Por outro lado, como aspecto negativo, tinha-se o longo processo de exploração, além da miscigenação. Entenda-se que, para este autor, a miscigenação era um aspecto positivo, contudo, devido ao ideal de branqueamento, essa característica era considerada a origem dos males de nossa formação social ${ }^{4}$. A 'democracia racial' de Freyre e o 'brasileiro cordial' de Hollanda foram logo disseminados, mas outras visões surgiam reformulando ou contestando ambos os mitos raciais. Entretanto, o fato é que a visão de um país racialmente democrático prevalece no imaginário da população brasileira (WILLEMAN, 2007, p.68).

É possível verificar com muita facilidade [e pouca satisfação] em bases de dados como IBGE, PNAD, PNUD e outros, a diferença de classe entre negros e brancos e entre homens e mulheres em nosso país que, combinada com elementos relativos à mortalidade infantil, mortalidade materna, mortalidade juvenil, índice de mortes violentas, acesso à escola, nível de alfabetização, quadro de distribuição por ocupação econômica, distribuição regional, acesso ao ensino superior, acesso à infraestrutura urbana, formam um complexo e sociologicamente rico, panorama que já não permite que se diga, sem alguma ironia ou desfaçatez, que não há diferenças raciais ou de gênero no país tropical que,'... em se plantando, tudo dá...'. Consideradas descartadas as teorias quanto à inferioridade biológica, do negro e do mestiço, da mulher e do gay, a passiva conformidade dos discursos 
oficiais e a morosidade legislativa e executiva quanto à questão da diáspora africana no Brasil provam que as representações sociais fortemente inculcadas em nosso país através dos discursos 'científicos' biologizantes ainda são deveras impactantes na realidade social.

Muito embora tenhamos tido avanços no acesso à educação em vários níveis, o GAP 5 entre o acesso de brancos e negros persistiu pouco alterado e nunca chegou à zero ou se inverteu. Para Henriques (2001), esse fator impressiona e mostra que o padrão de discriminação racial na educação manteve-se estável entre gerações. Afirma o autor, que as políticas de acesso universal e progressão continuada desenvolvidas nos últimos anos obtiveram um êxito parcial, pois a análise separada dos dados educacionais dos jovens brancos e negros mostra que "o desempenho não é homogêneo entre as raças". (HENRIQUES, 2001, p.38). Tal afirmativa é corroborada por Munanga $(2010, \mathrm{~s} / \mathrm{r})$ em comentário à recente audiência pública sobre as cotas raciais na UNB. Diz que:

Ela se fundamenta, (...) na situação estrutural das relações entre brancos e afro descendentes que, segundo estatísticas de IBGE e IPEA, apresenta um tão profundo abismo acumulado em matéria de educação que jamais poderá ser reduzido apenas pelas políticas macrossociais ou universalistas.

Já as estatísticas sobre mortalidade materna, os estudos de Martins (2001), mostram dados muito mais alarmantes: o risco de mortalidade materna para é 7,4 vezes maior para mulheres negras em relação às brancas. Quanto às mortes violentas [assassinatos] o que Soares (2007, p.26) verifica, dentre outros fatores, é que "... a diferença na probabilidade de morrer vítima de homicídio entre um homem com 1 a 3 anos de estudo e outro com ensino superior é de 236 por 100 mil", o que nos leva de volta à primeira estatística de Henriques que verifica o GAP de escolaridade entre brancos e negros, que, inclusive, em ternos de nível superior, se torna maior ainda do que nos níveis fundamental e médio, nos indicando, em consequência, maior tendência de mortes violentas entre jovens negros do que para qualquer outro grupo social em nosso país. Se esse coeficiente aqui estimado pode ser interpretado como relação causal, então podemos afirmar que os resultados desta pesquisa são muito relevantes.

Quando pensamos na situação LGBT no Brasil, o panorama é ainda pior, para além da mera discriminação de raça e classe. Sabe-se de estudos como o de Mott $^{6}$ sobre a quantidade de assassinatos de homossexuais no Brasil, entretanto, a coleta de informações é feita apenas a partir das ocorrências divulgadas na mídia, o que conclui por sua subnotificação.

Outra característica dos assassinatos homofóbicos é sua condição de 'crime de ódio', incluindo muitos golpes, múltiplos instrumentos e tortura. Um dos avanços mais recentes que contemplam todas as discriminações aqui descritas foi a criação, no Rio de Janeiro, de uma ouvidoria especial para atendimento Centro de Referência e Promoção da Cidadania LGBT, o Centro de Referência e promoção da Liberdade Religiosa e contra a intolerância, outros.

Em seus estudos sobre os movimentos sociais, Gohn $(2008,2010)$ verifica que, em geral, as mulheres são maioria numérica nos movimentos sociais, não apenas nos movimentos feministas e de gênero. Entretanto, algo que chama à atenção é o fato de que esta participação não implica na diminuição da violência doméstica, por exemplo, indicando que sua participação na esfera pública já obteve francos avanços, mas ainda não foi capaz de eliminar a violência de gênero da sociedade patriarcal.

As elites intelectuais e econômicas que componentes da sociedade brasileira em todos os tempos sempre se encarregaram de divulgar a imagem de um Brasil da 'democracia racial' do mundo, o que impediu, por muito tempo, o reconhecimento por grande parcela da sociedade quanto à existência de um problema racial no país. Por outro lado, as questões relativas à desigualdade e ao preconceito de gênero, sempre ficaram relegadas ao plano privado, como se tratasse de questões menos importantes já que pareciam afetar diretamente apenas àqueles sujeitos de menor 'valor' social, como mulheres, homossexuais e crianças. Ambos os engôdos - o da ausência do racismo e o da desimportância da violência de gênero - são frutos da mentalidade maniqueísta e conservadora judaico cristã predominantemente em sua versão mais retrógrada baseada na estratificação de classe de dominância no Brasil colonialista.

A história nos mostra que vários fatores contribuíram para isso e dentre eles, o principal é o econômico. A população negra, bem como os nativos brasileiros, as mulheres e as crianças são os que mais sofreram e ainda sofrem com as desigualdades sociais e com o preconceito. $\mathrm{O}$ preconceito racial, de gênero e o de classe informam o preconceito religioso vêm atingindo essa população, a partir do momento em que não há respeito às formulações jurídicas elaboradas visando à coibição desses fatos na sociedade ocidental. O primeiro passo para superação dessa situação seria admitir que no Brasil ainda há violências motivadas pelo preconceito, hierarquização e discriminação 
racial, de gênero e de classe (dentre outros). Esse processo cumpre a necessidade de emancipação desses grupos subalternizados, na medida em que se baseia em processos socioeducativos de formação de identidades emancipatórias para formação de novos ethos, para além dos territórios físicos dos terreiros, mas da sociedade brasileira como um todo. No caso da abrangência dessa discussão implicada na lógica religiosa afro-brasileira, cabe lembrar que os valores que a informam, mesmo considerando alguns elementos de disputa internos, não coadunam com a lógica dualista e estratificadora ocidental, não predominando as divisões com que operam formalmente no país. O negro, as mulheres e os homossexuais ainda são vistos como sujeitos indesejáveis à manutenção da 'higiene social', portanto, é muito útil a invisibilização do conflito, pois não permite francos avanços para a eliminação do preconceito, sendo prática nacional mais comum a do racismo velado e da invisibilização ou desvalorização da importância das violências cometidas contra mulheres e homossexuais e mesmo crianças, na medida em que identificamos a violência contra estes, como resultado da ideologia de gênero que informa a superioridade dos adultos e homens perante os demais sujeitos da família. Essa situação indica como se dá a disseminação do racismo cordial e da violência de gênero e sua repercussão negativa no cotidiano da população negra, feminina, infantil e gay.

Se for verdade que nossa identidade se completa pelo olhar do outro, é fundamental que se modifique a forma de o outro nos olhar, reconstituir outra identidade, em termos de reconhecimento do outro. Munidos dessas identidades emancipatórias e coletivas, esses sujeitos estariam aptos à entrada na esfera pública para proposição de suas agendas políticas coletivas em pé de igualdade para concorrência com os valores que informam a sociedade capitalista. A condição ideal para essa entrada legitimamente livre na esfera pública da democracia representativa para produção de direitos de igualdade não apenas formais, mas factuais, se daria apenas a partir da precondição da satisfação de aspectos relacionados aos direitos fundamentais da pessoa humana, como trabalho, alimentação, habitação e livre comunicação já que não havendo, grande seria a possibilidade de estes sujeitos negociassem suas agendas coletivas por interesses individuais como pequenas quantidades de insumos imediatos para a reprodução de sua vida material, partindo, portanto de uma lógica procedimental do campo do formal para uma política deliberativa onde se procura superar o modelo de esfera política onde predominam as figuras do cliente (cidadãos) e do fornecedor de serviços
(Estado).

A observação do campo empírico nacional, contudo, mostra que, para além do ideal, há processos contraditórios na esfera pública que confirmam a validade da formação da vontade política, pois as formulações jurídicas que não partiram da formação de um 'médium jurídico' dos grupos demandantes não saíram francamente do âmbito do direito formal para atuar no plano factual. Portanto, mostra-se fundamental a formação de identidades coletivas a partir de valores éticos alternativos à lógica da dominação econômica, de gênero e de raça.

Uma das formas de resistência negra mais eficazes, no sentido de garantia da permanência deste grupo étnico-racial, no cenário nacional, são as religiões de matrizes africanas. Nestes territórios geográficos e simbólicos, a composição cultural que os define enquanto religião inclui não apenas aspectos estritamente ritualísticos, mas também aspectos materiais relacionados à indumentária, culinária, arquitetura e logística; outros de caráter mais menos material como a língua, musicalidade; e outros mais sutis como a preservação da tradição da oralidade, dos modos de agir, ser, tratar, comportar-se. Neste sentido, acepções ligadas à divisão social de gênero estão diretamente afetadas.

Conforme Vinagre Silva (2007, p.05) nos alerta:

A geografia cultural dos terreiros expressa, pois, uma ocupação sociopolítica, uma vez que os Ilês são casas religiosas, mas também são espaços étnicos, casas de moradia, de acolhimento, assim como espaços de prestação de serviços assistenciais. Aí, as relações de parentesco consanguíneo e religioso-, articuladas às relações de gênero, interétnicas e de classe, modelam e regulam relações, não só religiosas, mas afetivas, econômicas, socioculturais e éticas políticas Através da repetição da oralidade e de práticas vivas que habitam a memória [...] ressignificadas cotidianamente nos territórios dos Ilês, constituem elos entre o presente e o passado, elos entre o mundo contemporâneo real e o mundo mítico, elos entre o território religioso dos terreiros e a vida social.

Neste sentido, estes territórios chamados 'Ilês', 'Casas de Santo', 'Terreiros' apresentam-se como uma alternativa de sociabilidade e de vivência 'outra', para além do repertório de práticas religiosas, mas de vivências que subvertam as relações de poder e hierarquias hegemônicas dos grupos no poder na 
sociedade eurocêntrica e capitalista. Uma vez inserido através da presença material e simbólica do 'ilê' no seio desta sociedade posta com suas estratificações de base hierarquizante, este conjunto de valores atua como processo socioeducativo capaz de operar transformações sociais éticas e políticas. A começar pela negação do falocentrismo ocidental a partir da grande valorização da figura feminina seja no panteão de deidades cultuadas, seja na autoridade das sacerdotisas componentes do culto. O papel destas sacerdotisas, não maior nem menor que os dos sacerdotes e demais componentes do culto e das confraternizações, de cumprir as necessidades ritualísticas não se limita a um conjunto de práticas decoradas e encenadas naquelas datas festivas ou naquele espaço físico estrito e limitados asceticamente. Percebe-se, claramente, a interpenetração das práticas rituais nas práticas particulares e, de fato, uma práxis que exige comunhão entre os membros. Em muitas religiões, às mulheres são delegadas responsabilidades do 'cuidado do outro' e lhe são dados cargos de menor prestígio, o que não ocorre no candomblé no sentido da subalternização. O cuidado é feito por todos, sem diferenciação sexual ou de gênero e o prestígio é igualmente dividido, respeitando mais os valores ligados à 'maturidade mística' do que propriamente geracional.

Ainda conforme Vinagre Silva (2007, p.06), esses espaços:

Pretendem ser tendencialmente territórios libertários, plurais, dinâmicos, que articulam tradição e contemporaneidade, norma/interdição e liberdade. Acima de tudo, trata-se de espaços de poder perpassados por significados emblemáticos de identificação e de sentimento de lealdade, inclusão (de todos os excluídos), pertencimento, com possibilidade real de reafirmação étnica. Exatamente porque é um espaço de acolhimento, possibilita a incorporação do outro, do excluído, do diferente, do discriminado: negros/nãonegros, homens/mulheres/crianças, indivíduos de diferentes orientações sexuais e pertencentes a distintas frações de classe, inclusive muitos discriminados, como os portadores de deficiência e de comprometimento mental, que não teriam lugar em outras práticas religiosas. No terreiro de candomblé, os segmentos subalternizados da sociedade podem experimentar a possibilidade de ascensão social, e de desenvolvimento de uma nova sociabilidade, metamorfoseando seus lugares de desvantagem social em posicionalidades de prestígio, geralmente ligadas à hierarquia religiosa. Aí as mulheres, inclusive as negras pertencentes à classe social mais pauperizada, ocupam altos cargos, diferentemente do que se verifica em outras religiões.

Maria Salete Joaquim (2001, p.53), mostra que, portanto, a conscientização parte da necessidade de preservação da identidade comum a esse grupo específico, ou seja, o caráter e o modelo de conduta "independentes reforçados através da interação social, sobretudo quando as pessoas recebem um tratamento discriminatório por parte de outros grupos".

No caso do Ilê Omi Ojuarô, nosso objeto de estudo, a partir das entrevistas, percebemos que, nesta Comunidade de Terreiro específica, a atuação do Serviço Social se dá a partir da presença da Assistente Social Rosa ${ }^{7}$, no momento das reuniões coletivas com a presença dos adeptos do culto.

Rosa faz parte da Comunidade de Terreiro como filha de santo de mãe Beata de Iemanjá, e está iniciada $^{8}$ na religião há pouco tempo, o que se pode chamar de "iyawô. Segundo ela, ainda "tem muito que aprender no tocante a religião". (47 anos, Rio de Janeiro, 01 de junho de 2009).

Em entrevista cedida no dia 06 de abril de 2009 às 10h45min, Adailton ${ }^{9}$, filho de Iyá Beata de Iemanjá, fala que embora a comunidade seja destituída de alguns serviços públicos, existe uma flagrante diversidade de pessoas com valores e interesses próprios e diferentes capitais econômicos e culturais, $\mathrm{e}$, mesmo sendo algumas pessoas de poder aquisitivo mais baixo, almejam uma ascensão social que não passa pelos mesmos valores ou interesses da sociedade emergente, o que significa que a orientação política da casa procura desenvolver entre seus adeptos ações e atividades que fomentem uma autoestima, trabalhando com a possibilidade de mobilidade social baseada em conceitos religiosos afro-brasileiros como a valorização da cultura africana e afro-brasileira, a valorização dos mais velhos, a valorização dos indivíduos independente de status, dentre outros, resgatando entre seus membros religiosos uma visão de mundo que intercambia com a sociedade contemporânea, mas não sede à mesma por princípios que consideram fundamentais.

Para ele: "o olhar de vitimização da sociedade de periferia, das comunidades, tem que ser revisto o tempo inteiro" principalmente pela elite intelectual, pois os valores das pessoas da comunidade periférica são diferentes dos valores da sociedade "dita mais 
Candomblé no Brasil: Traçando uma Nova

Geografia Social de Gênero, Raça e Classe, a

partir de uma Proposta de Sociabilidade Outra

ampla" (41 anos, Miguel Couto, seis de abril de 2009).

Segundo nosso entendimento sobre estas declarações, o entrevistado quer dizer que, embora os adeptos das casas de santo possuam ambições, ele entende que estas são diferenciadas das comumente veiculadas em outros âmbitos da sociedade. Para ele, a formação religiosa influencia na criação de uma identidade que impacta em construção e cultivo de valores e, portanto, na forma destes indivíduos verem a vida e todos os aspectos a ela inerentes. A crítica que Adailton apresenta, vai no sentido de que esta sociedade, dita mais ampla, olha para o morador da periferia e o sujeito mais pobre com a certeza de que ele é uma vítima em todos os sentidos. Segundo o entrevistado, esta apreensão não é absoluta uma vez que muitas das ambições de consumo e status passam a ser relativizadas pela construção de valores outros, como a solidariedade e a relativização do valor dos bens materiais e grupos de status construídos, sobretudo na sociedade de consumo capitalista. Entendemos, contudo, que é preciso que haja toda uma rede de serviços básicos de saúde, de justiça, e de equidade social, assim como é oferecido ao resto da sociedade.

Segundo o líder religioso, a comunidade tem uma formação cultural específica em que as pessoas pertencem a um grupo em que as relações sociais são muito fortes, elas se ajudam mutuamente, e essa ajuda é primordial para 'os laços sociais' serem mais fortes, afirmando que:

A gente pode estar percebendo um pouco isso do que 'Durkhein' fala o que seja a solidariedade mecânica e a solidariedade orgânica. Entre esses dois mundos paralelos que a gente vai perceber que o mundo, dito civilizado, desenvolvido, perde um pouco com a racionalidade, com a individualização do sujeito, e que nessas comunidades as pessoas são extremamente participativas e solidárias umas com as outras (41 anos, Miguel Couto, seis de abril de 2009).

Podemos notar que, de acordo com Adailton, em se pensando no contexto neoliberal, marcado pela globalização e individualização das pessoas de forma cada vez mais acirrada, as comunidades de periferia servem como forma de proteção e preservação.

Diante deste fato, Sueli Carneiro e Cristiane Cury (1982, p.176), discorrem:

Quando a sociedade capitalista, através das relações sociais de produção que estabelece, retifica o individuo, desumanizando suas relações; quando propõe uma visão individualizante de mundo, destruindo núcleos comunitários remanescentes de outros momentos históricos; quando fundamenta uma ciência que tem como tarefa a dessacralização da cultura, forjando seu reino na terra, parece significativo o fato do candomblé se expandir vertiginosamente, levando-nos a crer que este se coloca como uma forma de resistência à fragmentação da existência do homem brasileiro, seja no plano concreto, seja no plano ideal da explicação ontológica.

Como nos mostram as autoras ${ }^{10}$, este sistema mítico do qual faz parte o candomblé, tenta dar conta da totalidade do indivíduo enquanto um ser humano, reconhecendo seu passado de forma a the proporcionar um futuro com melhores condições materiais e espirituais dentro da sociedade capitalista.

Adailton procura mostrar que a individualidade das pessoas da comunidade não chega a afetar os relacionamentos dizendo que esta:

...Não é uma visão egoísta de viver num mundo desenvolvido, muito pelo contrário, é importante que as pessoas se cumprimentem que as pessoas saibam onde quem está morando, quem é o quê, e aonde se vai. É uma relação de pertença muito forte e nós percebemos que as comunidades de terreiros de religião de matriz africana (...) ainda têm em seus núcleos, nos seus espaços, esta relação [é] muito forte, nós vamos perceber isso (41 anos, Miguel Couto, 13 de abril de 2009).

Interessante perceber no relato do líder religioso e também cientista político que há uma grande diversidade em termos de capital intelectual, cultural, econômico e simbólico dentre os membros da comunidade de terreiro.

Conforme sua fala abaixo, percebemos a formação de um ethos diferente do da sociedade vigente:

Numa comunidade de terreiro você tem doméstica, doutores, intelectuais, políticos, profissionais liberais, profissionais autônomos. Você tem uma gama de indivíduos que compõem uma sociedade mais ampla. É aí que eu creio que, para a contemporaneidade, para essa sociedade dita desenvolvida, racional, lógica, as 
comunidades de terreiros têm muito a contribuir para esse olhar das relações humanas mais próximas, que trabalha exatamente com este princípio de comunidade, de coletividade. Eu acho que esta contribuição é fundamental para essa sociedade que caminha cada vez mais pra essa individualidade, para esse egoísmo social, que trabalha em cima de lucros, que trabalha em cima de números, e em cima de uma lógica que acaba resumindo um pouco a capacidade do ser humano de ver algo além de seu umbigo. Nós percebemos aqui no Ilê Omiojuarô, na casa de Mãe Beata especificamente, que no dia de festividades temos 150 pessoas envolvidas diretamente, fora o público que vem assistir às festividades. Isso se chama controle social, isso se chama organização política, isso se chama solidariedade social, equidade social, relativização dos papéis sociais. Porque você vai encontrar domésticas que vão ter um posto sacerdotal, às vezes, em um grau hierárquico acima de um engenheiro, e esse engenheiro, às vezes, enquanto um recém iniciado, tendo que ter respeito. Isto não quer dizer que estes papeis sociais estão presos a isso: o menos favorecido socialmente e quem tem os cargos mais altos. Não! $O$ engenheiro também pode ser um sacerdote de tamanha importância. O que eu estou querendo dizer é que esses papéis que a sociedade identifica quanto papéis de status social, dentro das comunidades de terreiros, não vai ter tanta importância. E também não estou querendo dizer que, esse tipo de inversão de valores dentro de uma ótica de matriz africana não venha a acontecer, pode acontecer. Porque o tempo inteiro há um bombardeamento dessa visão de mundo neoliberal, de hierarquia social, e de status social. Então, isso tudo é muito importante para que nós tenhamos um olhar, uma percepção, para estar vendo este tipo de contribuição, de relativização de papéis sociais (41 anos, Miguel Couto, treze de abril de 2009).

Podemos perceber que há uma grande unidade na diversidade dentro deste espaço religioso. E de acordo com Bastide (2001, p.25):

A religião do candomblé, embora africana, não é religião só de negros. Penetram no culto não somente mulatos, mas também brancos e até estrangeiros. É preciso dissociar completamente religião e cor da pele. É possível ser africano sem ser negro.

Neste sentido, Adailton procura mostrar que esta diversidade, embora passe por alguns desafios através dos atritos / conflitos pela inversão do papel de status social, não chega a atrapalhar o culto religioso, pois há uma organização política religiosa na qual o que impera é o respeito mútuo.

O terreiro possui um trabalho na comunidade de Miguel Couto e adjacências, que vai além do culto religioso de candomblé: ele presta um serviço de assistência material e simbólica à população em situação de vulnerabilidade social e, por vezes, marginalizada.

A Comunidade de Terreiro, durante muito tempo, trabalhou em parceria com diversas instituições, como a Ong de mulheres negra chamada CRIOLA; a organização VIVA RIO; (uma organização não governamental brasileira sediada no Rio de Janeiro que luta contra a exclusão social, a promoção da paz e do desenvolvimento social). ISER; (Instituto de Estudo das Religiões); o ATO-IRE; (tem como objetivo denunciar e combater as formas de racismo, discriminação e preconceito racial, social, sexual e religioso, especialmente praticados contra a população negra ou afro-descendente - desmembrou-se na rede nacional de religiões afro-brasileiras e saúde; O CEAP (Centro de Apoio a Populações Marginalizadas), que hoje em dia trabalha com a questão da intolerância religiosa; o Cedoicom; que é uma ONG de mulheres negras com vistas a contribuir com a eliminação de todas as formas de preconceito, discriminação, e opressão sofrida pelas mulheres; a organização Felipa de Souza (Organização Internacional empenhada no combate às violações dos direitos humanos de lésbicas, gays, bissexuais, pessoas transgêneres e portadoras do vírus HIV/AIDS), dentre outras.

Exatamente por este perfil de questionamento e potencial de possibilidade de superação da subserviência de longa duração, imposta não apenas aos grupos de cor, mas de classe, gênero, orientação sexual e, objetivamente, neste caso, religiosa, que a história das religiões de matrizes africanas no Brasil sempre esteve permeada de perseguição, violência e tentativas de silenciamento desde suas primeiras expressões até os dias de hoje.

Sabemos que muito do sincretismo religioso, existente hoje, é fruto das estratégias de existência/permanência dos africanos e seus descendentes para exercer seus cultos, sua língua, suas 
práticas. Vem daí, por exemplo, a associação dos Orishas com nomes de santos católicos como Ogum sendo identificado como São Jorge, Oxum como Nossa Senhora da Conceição, Oxalá como Jesus Cristo, Oya ou Iansã como Santa Bárbara e muitos outros. Esta associação de nomes aconteceu e permaneceu acontecendo até os dias atuais devido ao fato primeiro durante o Brasil Colônia, quando os escravos, impedidos de cultuar suas deidades, fingiam estar cultuando as deidades do culto católico. Aliás, esse significa apenas um dos saques identitários perpetrados pelo branco contra o negro. A proibição do exercício do idioma natal, bem como da auto-identificação por seu próprio nome de batismo foi comum durante toda a escravidão, o que provocou a perda de muito das características identitárias deste povo, cujas características culturais foram cerceadas e até mesmo tornadas crime - como o caso da capoeira.

Depois de abolida a escravatura formalmente, com a organização de casas de santo, muitos foram os casos de violação violenta e institucional - com a intervenção policial e de outras 'autoridades' - de templos já que nosso país racista sempre se autoproclamou católico.

Casos como estes são noticiados até os dias atuais, como no caso ocorrido em 30 de Salvador - Bahia em que o Ilê Axé Opô Afonjáfoi vítima de atos de vandalismo em que marginais invadiram o quarto de Oxalá e destruíram as instalações do espaço sagrado ${ }^{11}$; ou no caso noticiado pela mídia carioca em que um templo de umbanda no Catete foi destruído por dois jovens brancos fundamentalistas de religião evangélica ${ }^{12}$; ou no caso em que a fotografia não autorizada de crianças netas de Iyálorisha foram estampadas em livro evangélico como 'filhas do diabo'13.

Felizmente, conforme pudemos verificar, nos dois últimos casos foi possível a confirmação da autoria do caso e sua consequente punição, sendo o caso ocorrido no Catete em 2008 o primeiro caso em que houve condenação enquadrada como crime de intolerância religiosa. Para os movimentos sociais que pregam a tolerância e o diálogo inter-religioso, esses são pequenos avanços, porém, o início da caminhada necessária para a garantia da concretude da sociedade democrática com cidadania para todos os cidadãos independente de classe, gênero, religião, etc.

\section{Serviço Social, Projeto Ético Político e Código de Ética Profissional}

Ao nos aproximarmos dos dilemas da sociedade brasileira não podemos deixar de notar que, a partir da década de 1980, com a crise econômica nacional e a quebra de alguns paradigmas inerentes a um movimento macrossocial de efervescência da globalização e da mundialização, uma nova sociedade passa a ser configurada, com grandes transformações não só econômicas, mas também, culturais e sociais, ao mesmo tempo em que aconteciam as lutas dos setores organizados pelos direitos democráticos (BONETTI, 2006, et. al. p.13).

Como tentativa de dar respostas aos problemas sociais pululantes, ou melhor, assumindo a empreitada de promover um enfretamento e consequente superação das expressões da Questão Social, os profissionais do Serviço Social, enquanto categoria, empreenderam massivo investimento, na produção teórica e também na dimensão política da profissão. Neste contexto histórico, percebemos que os Assistentes Sociais se aproximavam dos movimentos sociais, que evoluíam (no sentido de crescimento quantitativo e representativo) deveras, como os de cunho étnico-racial, feministas, movimento gay, e outros.

Conforme assinala Willeman (2007, p.30):

Estes são movimentos sociais que tomavam força concomitantemente à desestruturação progressiva dos movimentos sociais de caráter exclusivamente de classe. Movimentos sociais paulatinamente esmaecidos pela desorganização espacial do trabalho e dos trabalhadores. O desestímulo às organizações sindicais pela concorrência, fruto do crescente desemprego estrutural e do sepultamento da centralidade da categoria "classe", enquanto direito primordial, e da categoria "trabalhador", enquanto demandante de direitos. Neste marcante momento histórico, político e econômico brasileiro, emergem com mais força - e até mesmo estimulados pelos detentores de capital de orientação neoliberal, numa sociedade em franca abertura capitalista - os diversos movimentos sociais que, se por um lado abriam mais a discussão dos direitos sociais, por outro, eram entendidos enquanto fragmentação das lutas sociais e abandono da visão da totalidade, distanciando a "classe trabalhadora" do seu maior oponente: a estrutura de dominação de classe e exploração capitalista.

Especificamente, no que tange à discussão da raça no contexto da emergência dos novos movimentos sociais, em diversos aspectos, não há nada que a diferencie dos 
Candomblé no Brasil: Traçando uma Nova

Geografia Social de Gênero, Raça e Classe, a

partir de uma Proposta de Sociabilidade Outra

demais movimentos sociais emergentes (como os movimentos ecológicos, gay, feminista, e outros) que foram catalizados, então. Evidentemente há também diversos eixos, em especial o histórico e econômico, que dão maior especificidade ao eixo do movimento negro no Brasil, em função da história de país escravista.

Como parte dessas mudanças, vários movimentos sociais que já vinham se desenvolvendo no Brasil ganham mais força, dentre eles, o movimento negro. Vale ressaltar, que este movimento é tardio no Brasil, se pensarmos na evolução do movimento negro nos Estados Unidos, por exemplo, com o surgimento e a atuação, do grupo Panteras Negras ${ }^{14}$. Este grupo tinha como finalidade de origem patrulhar guetos negros e proteger seus membros contra todos os tipos de violência, praticadas pela polícia.

Mais tarde, esse grupo tornou-se um grupo revolucionário com inspirações marxistas atuando na defesa dos direitos da população negra e com interseções fortíssimas das questões de gênero ${ }^{15}$. Pensando nessa discussão, observamos que o código de ética profissional do Serviço Social de 1993 tem como um dos seus princípios a opção por um projeto profissional vinculado ao processo de construção de uma nova ordem societária, sem dominação, exploração de classe, etnia e gênero.

Podemos perceber, através destes princípios, que esta inclusão de categorias de sujeitos e questões vem a ampliar a visão sociopolítica do profissional do Serviço Social ao tratar das referidas questões, que consideram o compromisso ético político da categoria dos assistentes sociais para com estes grupos. O Projeto Ético Político do Serviço Social se concretiza junto ao projeto de sociedade. A construção de uma nova ordem social fundamentada nos princípios da liberdade, equidade, justiça social e da democracia, só poderá se realizar a partir do momento em que cada ser humano independente de cor, raça, etnia e gênero, puder desempenhar a sua cidadania.

Desta forma, pensamos que esta construção do referido projeto vem como resposta às demandas políticas por respostas a suas inquietações, na esfera da aquisição, resgate e manutenção de direitos sociais, econômicos e políticos nos marcos da construção de uma sociedade democrática. Diante deste panorama, os Assistentes Sociais são constantemente levados ao questionamento da nova ordem social e das estratégias políticas que possam usar para intervir nestas questões e proteger, deste modo, a direção política do projeto profissional.

De acordo com Paiva (2006, p.198):
O sonho da democracia, a ser consolidado, sobretudo pelo enfrentamento real da desigualdade, mantém-se atento à agenda de proposições que os movimentos sociais vêm construindo

Após considerações sobre a emergência dos movimentos sociais na arena política, os chamados 'novos movimentos sociais' (ABRAMO, 1994), como o MST (Movimento dos Sem Terras), LGBT, Movimentos Feministas, Ambientalistas, de orientação para as necessidades especiais de portadores de deficiências, bem como questões geracionais, e outros, caberia aqui uma análise mais detida sobre os movimentos relativos à questão do racismo e da discriminação racial. Pois grande parte da população negra vive em péssimas condições de sobrevivência, sem emprego e moradia, representando a maioria da nossa população.

Conforme nos diz Agier (1996, p.105):

Numerosa nos vários extratos do trabalho dito informal (em que a rede das relações de trabalho se funde com a rede das relações de família e de vizinhança e, muitas vezes, com uma unidade de condição racial).

Como parte formadora da nossa sociedade, sobre os diversos prismas, os negros são numericamente grande parte da nossa gente. Muito embora estatísticas oficiais apresentem historicamente um número menor do que o que se percebe empiricamente sobre o quantitativo de negros no Brasil, entendemos que as razões para isto são explicadas nas matrizes do racismo cordial que sempre orientou as relações brasileiras de sociabilidade.

Atualmente, percebemos essas estatísticas mudando as proporções outrora apresentadas e podemos compreender esse movimento na medida em que acompanhamos não apenas ações de positivação das identidades étnico raciais do grupo de descendência afro brasileira, como a implementação de políticas compensatórias para estes grupos, as chamadas ações afirmativas ${ }^{16}$. Tais ações visam combater as desigualdades sociais brasileiras, dando oportunidades a esta parcela da população, que durante séculos foi maltratada e discriminada, dentre outras formas de exploração que ainda hoje podemos notar.

Acreditamos que esta igualdade deve ser aplicada na forma da Lei, para efetivamente diminuir-se as desigualdades e as diferenças sociais e, somadas às políticas de cotas, para que possa haver uma reparação histórica pelos danos causados a determinados grupos da população que hoje se apresentam nos estudos sob

Estela Martini Willeman 
as mais diversas alcunhas ${ }^{17}$, como excluídos, vulneráveis, desnecessários, e outras, que venham a necessitar de proteção especial e assim termos 'uma sociedade livre, justa e solidária'.

Com critérios de autoclassificação, de forma a reler/resgatar/construir/ressignificar uma identidade negra positiva, a política de cotas - uma política pública - tem como objetivo corrigir a desigualdade e discriminação racial sofridas pela população negra desde o início da formação social do país, que adotava uma classificação que considerava alguns seres melhores que outros (Ibase, 2008,p.09), e que ainda tem suas mais profundas marcas nas expressões de racismo atuais. Acreditamos que a inserção do Assistente Social nessa luta pode ser de grande contribuição, a partir da análise de alguns dos princípios fundamentais do Código de Ética Profissional, e que consideramos de extrema importância para a eliminação de todas as formas de preconceito e discriminação na sociedade brasileira.

Como afirma Willeman, (2007, p.27):

(...), fica bastante clara a orientação e forte inclinação do profissional do Serviço Social em relação ao perfil delineado e classificado por Gramsci (1968) como intelectual orgânico, em contraposição ao que ele classifica enquanto intelectual tradicional (...). A diferença essencial entre ambos, pode ser descrita em apenas uma palavra: compromisso. Compromisso que se julga ético, justo e emancipador, mas, ainda assim, compromisso.

Desta forma, observamos o reconhecimento da liberdade como valor ético central, a defesa intransigentemente dos direitos humanos, a ampliação e consolidação da cidadania, a defesa da democracia, posicionando-se em favor da equidade e da justiça social, bem como o empenho à eliminação de todas as formas de preconceito, garantindo o pluralismo, e também uma articulação com movimentos de outras categorias profissionais, no exercício da profissão sem discriminação por questões de classe social, gênero, etnia, religião, e dentre outras (CRESS, 2007).

Percebemos o Serviço Social amplamente implicado nessas lutas. Estes são alguns dos compromissos do Assistente Social que podem colaborar na luta organizada dos negros brasileiros, contra todas as formas de preconceito e discriminação e seu envolvimento nos movimentos sociais (onde acreditamos e percebemos claramente que grande parte da população envolvida é negra e pobre ${ }^{18}$ ) e também, a persistente luta na tentativa de combater o racismo e a desigualdade racial na qual se vê que:

(...), o Brasil nasce com as diferenças biológicas, raciais, 'coladas' com o lugar na economia, funções, tarefas, interdições. Esta não é, então, uma questão apenas de diferenças fenotípicas, porque geneticamente, tais características foram impregnadas de papeis sociais, funções, e tarefas. Houve, portanto, um projeto econômico, social e político de se criar um país, usando as diferenças (raciais) como elemento operacional (CASTRO, apud CRIOLA $^{19}$ ).

Para Castro ( $\mathrm{s} / \mathrm{d})$, estes fatos foram incorporados na cultura da sociedade brasileira, de tal forma que as diferenças raciais são vistas de maneira natural. O Assistente Social é um profissional capacitado para atender essas demandas inerentes à sociedade capitalista e racista, intervindo na realidade dessas minorias em termos de representação política ${ }^{20}$, que são em grande parte a maioria da nossa população.

De acordo com Iamamoto (2006, p.80):

Os Assistentes Sociais(...), formam uma categoria que tem ousado sonhar, que tem ousado ter firmeza na luta, que tem ousado resistir aos obstáculos, porque aposta na história, construindo o futuro no presente.

Entendemos, a partir do que nos mostra a autora, que construir o futuro no presente se refere ao fato de que, o que para muitos pode ser visto como uma utopia, para o Assistente Social passa a ser uma forma estratégica de futura ação não tão viável, mas necessária ao enfrentamento, e às lutas dos movimentos da população.

\section{[ln] Conclusões}

No término desta pesquisa, tivemos a percepção e certeza de que faltava muita coisa para se pensar em concluí-lo. Percebemos, também, o quanto temos a aprender diante do assunto estudado neste pequeno período de tempo da feitura do trabalho, mas admitimos o quão foi enriquecedor o conhecimento obtido através desta pesquisa.

Ao adentrar no universo das religiões de matrizes africanas para pesquisar como eles enfrentam o preconceito e a discriminação no campo religioso, constatamos que seus membros utilizam vários instrumentos de ações no combate ao preconceito e a discriminação em qualquer nível não se atendo 
simplesmente ao campo religioso.

Ao desenvolver a pesquisa, pudemos perceber como a sociedade brasileira, desde a sua formação social através da opressão e discriminação, vem tratando de forma diferenciada em decorrência da condição socioeconômica, de exclusão social, a população negra, mestiça e os nativos brasileiros. Alguns pontos importantes foram sinalizados condizentes à origem do preconceito e da discriminação racial no Brasil, um fato histórico que, se, por um lado, se torna mais evidente, por outro, não se mensura, pois poucas pessoas admitem o fato de serem preconceituosas em relação à cor e a raça, e etnia.

O mito da democracia racial está enraizado na sociedade brasileira, e mesmo não acreditando nela, a grande maioria dos brasileiros procuram praticá-la, ou mesmo dar a impressão do que o faz. Este fato, de acordo com Sansone (1996), tem suas origens no final do século XIX e início do século XX, com o ideal de branqueamento. A importância das ações afirmativas, como as políticas públicas em especial as cotas raciais para a população negra, vem ao encontro de uma reparação aos danos causados a esta população ao longo da história do Brasil.

A promoção da igualdade, de oportunidades, e o acesso às instituições do ensino superior para todos os que se encontram em determinados grupos discriminados através dos mecanismos, contribuem positivamente para a afirmação da identidade negra, tão rejeitada diante dos preconceitos e das discriminações impostos desde a escravização dos negros no período colonial. Sabemos que a forma de combate ao preconceito e a discriminação, bem como seus efeitos são através da legislação penal, e das ações afirmativas, e que este, é um tema contraditório na sociedade brasileira, tais discussões podem ser vistas como falta de conhecimento e incompreensão.

1 O NIEGRE - Núcleo Interdisciplinar de Estudos de Gênero, Raça/Etnia e Educação - foi um grupo de estudos, pesquisa e extensão criado e coordenado pela professora Estela Martini Willeman entre os anos de 2008 e 2009 na UNIABEU- Centro Universitário em Belford Roxo - Baixada Fluminense - RJ, e recebeu desta instituição parte do financiamento necessário para suas atividades de pesquisa a partir do PROAPE - Programa de Apoio à Pesquisa e Extensão Docentes. Guiomar Rodrigues de Oliveira Lima foi uma das estudantes do curso de Bacharelado em Serviço Social desta instituição que participaram ativamente deste núcleo. O presente trabalho é fruto das pesquisas de ambas as autoras com apoio de toda a equipe que integrava o grupo.

2 Nascida em 1931, iniciada no Candomblé de Salvador - BA, em 1944, é autora dos livros 'Caroço de Dendê' (1997) e 'Histórias que a minha avó contava'(2004); integra diversas instâncias da esfera das políticas públicas e ações afirmativas relativas às causas das mulheres, da negritude, das religiões de matrizes africanas, das desigualdades sociais como um todo. Ver mais em $<$ http://www.letras.ufmg.br/literafro/autores/maebeata/ dados.pdf $>$

$<$ http://www.informacao.andi.org.br/site/arquivos/mbi. pdf $>$.

3 Entrevista concedida à Revista Fórum em agosto de 2009. Disponível no site: $<$ http://www.revistaforum.com.br/sitefinal/EdicaoNoti ciaIntegra.asp?id_artigo $=7378>$. Consultado em $20 \mathrm{de}$ fevereiro de 2010 .

4 Esta ideia está contida na obra de Manoel Bonfim (1905) 'América Latina: Males de Origem'.

5 O termo GAP tem sido utilizado significando um intervalo, um espaço vazio, uma 'brecha' entre uma informação e outra. Antigamente o termo GAP era utilizado para determinar o espaço não utilizado entre uma informação e a próxima numa unidade de fita utilizada pelos computadores mainframe (Fonte: $<$ www.wikkipedia.com.br $>$ ).

6 Ver mais em $<$ http://www.atarde.com.br/cidades/noticia.jsf?id=140 $7864>$.

7 Rosa Monteiro de Carvalho, Assistente Social CRESS AS 15049, formada pela PUC Rio de Janeiro.

8 Iniciação diz respeito à 'feitura de santo' o que podemos dizer que a pessoa nasceu de novo para a vida. Estando limitada durante certo período, ao aprendizado religioso.

9 Formado em ciências sociais pela PUC Rio de Janeiro. Coordenador de campo da pesquisa de mapeamento dos terreiros do Estado do Rio de Janeiro pela secretaria especial de política e promoção da igualdade racial, PUC Rio. Membro da rede nacional de religiões afro-brasileiras de saúde. Coordenador executivo e cultural do INDEC, (Instituto de desenvolvimento cultural), uma instituição que está sediada no espaço físico da referida comunidade 
terreiro.

10 Muito embora o texto tenha sido escrito num contexto histórico outro quando não havia ainda o boon neopentencostal, consideramos que seja válido considerar ainda estas afirmações no sentido de que hoje percebemos uma nova e revitalizada atuação das religiões de matriz afro descendente através de sua organização ampla e política e dos processos de visibilização empreendidos..

$11 \quad$ Fato ocorrido em 15 de dezembro de 2009. Fonte: $<$ http://mundoafro.atarde.com.br/?p=2279 $>$.

$12 \quad$ Fato ocorrido em 02 de junho de 2008. Fonte: $<$ http://g1.globo.com/Noticias/Rio/0,,MUL587234$5606,00 . h t m l>$.

13 Fato ocorrido em 1992. Fonte: $<$ http://www.fazendomedia.com/novas/educacao09020 6.htm>.

14 Partido negro revolucionário estadunidense, fundado em 1966 em Oakland - Califórnia, por Huey Newton e Bobby Seale, originalmente chamado Partido Pantera Negra para Autodefesa (no original, 'Black Panther Party for Self-Defense', depois, mais conhecido como 'Black Panther Party', Panteras Negras).

15 Para maior aprofundamento sobre este aspecto, sugere-se a investigação da vida e obra de Kathleen Cleaver, cofundadora deste movimento, ainda viva e Professora Doutora da Universidade da Califórnia.

16 Ação afirmativa é um conjunto de ações privadas e/ou políticas públicas que tem como objetivo reparar os aspectos discriminatórios que impedem o acesso de pessoas pertencentes a diversos grupos sociais às mais diferentes oportunidades. Para maiores explicações,ver Instituto Brasileiro de Análises Sociais e Econômicas - Ibase - Cotas Raciais, Por que Sim? $-3^{\circ}$. ed. Ibase, 2008.

17 Para mais considerações,ver WILLEMAN, Estela. Da validade da busca de "inclusão" numa lógica excludente. In: Revista Virtual Em Debate. PUCRio. Ano 2006. Número 04. ISSN 1809-0842.

18 De acordo com Pedro Demo (2001), em 'Exclusão Social - Novas e Velhas Formas', politicamente pobre é a pessoa que sequer consegue saber que é pobre. Para o autor não há pobreza mais comprometedora do que a ignorância politicamente produzida ou mantida.

19 Este depoimento foi coletado em um material educativo produzido pela Organização Não Governamental de e para mulheres negras 'Criola', cujo site encontra-se no endereço eletrônico: www.criola.org.br.

20 Os negros não são uma minoria numérica e sim uma minoria política, percebe-se a falta de unidade de grupo realmente definido e unido junto à sociedade. Deste modo, as formas assumidas pela luta político-ideológica estão ligadas aos rumos teóricos pelos quais a relação raça/classe se desenvolveu.

\section{Referências}

ABRAMO, Perseu. Velhos Partidos e Novíssimos Movimentos. Revista Teoria e Debate. n. 24, mar, abr, maio. p.s/p, 1994.

AGIER, Michel. Etno política - a dinâmica do espaço afro-baiano. Cadernos Candido Mendes, estudos Afro-Asiáticos. n.22 - setembro, CEAA. 1992

BASTIDE, Roger. O Candomblé da Bahia: rito nagô. São Paulo: nova edição, Companhia das Letras. 2001

BONETTI, Dilsea A. (Org.)...(et. al). Serviço Social e Ética. Convite a uma nova práxis $-7^{\mathrm{a}}$ ed. São Paulo: Editora Cortez. 2006

BRASIL. Constituição. Constituição da República Federativa do Brasil: promulgada em 5 de outubro de 1988. Organização do texto: Juarez de Oliveira. 4. ed. São Paulo: Saraiva, 1990. (Série Legislação Brasileira). 1988

CARNEIRO, Sueli; CURY, Cristiane. O Candomblé. Texto apresentado ao $3^{\circ}$ Congresso de Cultura Negra das Américas, São Paulo. 1982

CARVALHO, José Murilo de. Cidadania no Brasil: o longo caminho. $9^{\circ}$ ed. Rio de Janeiro: Civilização Brasileira. 2007

CRESS $7^{\mathrm{a}}$ região - RJ. Assistente Social: ética e direitos - Coletânea de Leis e Resoluções. $4^{\mathrm{a}}$ ed. Rio de Janeiro: CRESS-RJ. 2007.

Declaração Universal dos Direitos Humanos de 1948-1998. Congresso nacional. Câmara dos 
deputados. Comissão de Direitos Humanos.

FREYRE, Gilberto. Casa Grande e Senzala. $34^{\circ}$. Ed. Rio de Janeiro: Record. 1992

HENRIQUES, Ricardo. Desigualdade racial no Brasil: evolução das condições de vida na década de 90. Brasília: IPEA. Texto para discussão n. 807. 2001

IAMAMOTO, Marilda Vilela. O Serviço Social na Contemporaneidade: trabalho e formação profissional - 10 ed. - São Paulo: Cortez. 2006.

MUNANGA, Kabenguele. Os perigos de uma crítica maniqueísta. Disponível em Folha de São Paulo On Line. Acesso em 27 de Março de 2010.

PAIVA, Beatriz Augusto de Sales; APOLINÁRIO, Mione. A Nova Ética Profissional: práxis e princípios In: Serviço Social e Ética - convite a uma nova práxis. $7^{\circ} \mathrm{ed}$. São Paulo: Cortez. 2006.

RIBEIRO, Darcy. O Povo brasileiro: A formação e o sentido do Brasil. $4^{\circ}$.ed. - São Paulo: Companhia das Letras. 1995.

SANSONE, Lívio. As Relações Raciais em Casa Grande e Senzala revisitadas à luz do processo de internacionalização e globalização. In: Maio, M. Chor. (Org.): Raça Ciência e Sociedade. Rio de Janeiro: Fiocruz/CCBB .1996

SOARES, Sergei Suarez Dillon. Educação: Um escudo contra o homicídio? Texto para discussão n. 1298. IPEA. Brasília. 2007.

VINAGRE SILVA, Marlise. O exercício do poder feminino na tradição étnico religiosa iorubá no Brasil: uma estratégia para concretizar direitos em uma sociedade globalizada e desigual. Foz Do Iguaçu: CBASS. 2007.

WERNECK, Jurema (Org.). Desigualdade Racial em números. Coletânea de Indicadores das desigualdades raciais e de gênero no Brasil. Rio de Janeiro: Criola, 2003. p. s/p.

WILLEMAN, Estela Martini. Marambaia: "ilha subversiva": múltiplos aspectos do processo de formação de identidades no "território negro" remanescente de quilombo2007. Dissertação (Mestrado em Serviço Social). Programa de PósGraduação em Serviço Social. PUC - Rio, Rio de
Janeiro - RJ.

Da validade da busca de "inclusão" numa lógica excludente. In: Revista Virtual Em Debate. n.4, PUC - Rio, p.s/p, 2006.

YEMONJÁ, Mãe Beata. Caroço de dendê: a sabedoria dos terreiros. Rio de Janeiro: Editora Pallas, 2002.

\section{Páginas Consultadas na Internet:}

Página da Organização Governamental Criola: $<$ www.criola.org.br> Acessada em 21 de março de 2009.

Página do Instituto Brasileiro de Análises Sócio Econômicas:

$<$ http://www.ibase.br/userimages/ibase_cotas_raciais 2.pdf $>$ Acessada em 15 de Abril de 2009.

Página da Organização Mundo Afro: $<$ http://mundoafro.atarde.com.br/?p=2279>. Acessada em 17 de junho de 2009.

Página do Jornal O Globo On Line: $<$ http://g1.globo.com/Noticias/Rio/0,,MUL5872345606,00.html >. Acessada em 17 de junho de 2009.

Página do Jornal Fazendo Média: $<$ http://www.fazendomedia.com/novas/educacao09020 6.html> . Acessada em 17 de junho de 2009. Aceito em 07 de março de 2011. 